\title{
Article \\ Application of Additives in Platycladus orientalis (L.) Franco Tending Shreds Compost in Forest
}

\author{
Xuan Li ${ }^{1}{ }^{1}$, Huijuan Bo ${ }^{1}$, Jialei Zhu ${ }^{1}{ }^{\circledR}$, Jiwei Zhang ${ }^{2}$, Jun $\mathrm{Hu}^{3}$, Fuyong $\mathrm{Mu}^{4}$ and Lishui Nie ${ }^{1, *}$ \\ 1 College of Forestry, Beijing Forestry University, Beijing 100083, China; 15201437913@163.com (X.L.); \\ bohuijuan@bjfu.edu.cn (H.B.); zhujialei99@163.com (J.Z.) \\ 2 Forestry Work Terminal, Gardening and Greening Bureau, Beijing 100029, China; jiweizhang0001@163.com \\ 3 Experimental Workstation of Water Conservation Forest, Gardening and Greening Bureau, \\ Beijing 100029, China; wangjiang@bjfu.edu.cn \\ 4 Beitaishang State Forest Farm, Gardening and Greening Bureau, Huairou District, Beijing 101407, China; \\ 13241688160@163.com \\ * Correspondence: nielishui@bjfu.edu.cn; Tel.: +86-136-0113-1465
}

Citation: Li, X.; Bo, H.; Zhu, J.; Zhang, J.; Hu, J.; Mu, F.; Nie, L. Application of Additives in Platycladus orientalis (L.) Franco Tending Shreds Compost in Forest. Forests 2022, 13, 253. https:// doi.org/10.3390/f13020253

Academic Editor: Tiina Maileena Nieminen

Received: 10 January 2022 Accepted: 2 February 2022 Published: 6 February 2022

Publisher's Note: MDPI stays neutral with regard to jurisdictional claims in published maps and institutional affiliations.

Copyright: (C) 2022 by the authors. Licensee MDPI, Basel, Switzerland. This article is an open access article distributed under the terms and conditions of the Creative Commons Attribution (CC BY) license (https:// creativecommons.org/licenses/by/ $4.0 /)$.

\begin{abstract}
This study aimed to explore the effects of different additives on tending shreds of Platycladus orientalis (L.) Franco. Two different additives (priming $0.2 \%$ and common compost $0.2 \%$ ) combined with $\mathrm{C}, \mathrm{N}$, and $\mathrm{P}$ adjustment of raw material treatments were tested on the temperature, moisture, $\mathrm{EC}, \mathrm{pH}$, lignocellulose degradation rate, nutrient content, and toxicity of compost. Priming made the compost temperature rise rapidly, and the peak temperature of the composting group with priming reached $51^{\circ} \mathrm{C}$. At the end of composting, the moisture in each treatment from high to low was in the order: common compost $>$ priming $>\mathrm{C} / \mathrm{N}, \mathrm{C} / \mathrm{P}$ adjustment only $>$ control group. The increase of EC in the treatments with additives was great, and the peak value of $\mathrm{EC}$ in the treatment of priming was $1.30 \mathrm{~ms} \cdot \mathrm{cm}^{-1}$, which was 3.9 times higher than that of the control group. At the end of composting, the decomposition rate of cellulose in priming compost was 1.7 times higher than that in the control group, and the hemicellulose decomposition rate in the common compost group was 3.2 times higher than that in the control group. By the end of composting, the $\mathrm{pH}$ value of the composts in additive treatments was above 7.0, and the $\mathrm{pH}$ value of the priming treatment was the highest (7.5). The highest content of organic matter was found in the priming treatment, which was $52 \%, 1.7$ times higher than that in the control group. The total nutrient content $\left(\mathrm{TN}+\mathrm{K}_{2} \mathrm{O}+\mathrm{P}_{2} \mathrm{O}_{5}\right)$ of additive treatments was higher than $5.0 \%$, and the priming treatment was $2.7 \%$ higher than that of the control group. By the end of composting, the germination rate and germination index ranged from $88 \%$ to $91 \%$ and $60 \%$ to $81 \%$. Except for the control group, the C/N ratio of other treatments decreased to below 25. Additives can accelerate the decomposition of raw materials, shorten the composting cycle, and improve the quality of composts, and the effect of adding priming is the most significant.
\end{abstract}

Keywords: Platycladus orientalis (L.) Franco; compost; forest stand; Huairou District; nutrient cycling

\section{Introduction}

China's forest resources have increased rapidly in recent years [1]. Platycladus orientalis (L.) Franco is the main afforestation tree species in the Beijing mountainous area because of its drought resistance and strong adaptability. At present, most Platycladus orientalis (L.) Franco Plantations are in the half-mature stage, with low quality and relatively fragile ecosystem functions [2], and tending can improve its productivity, stand structure, and soil fertility [3]. Platycladus orientalis (L.) Franco has the characteristics of bacteriostasis and corrosion resistance, and the proportion of branches, leaves, bark, and wood is about 16:17:8:40 [4]. After tending, it produces a large amount of residual organic waste, high quality, and a long natural decomposition cycle, which is easy to cause soil nutrient loss. Some researchers have produced $18-39 \mathrm{t} \cdot \mathrm{hm}^{-2}$ shreds after $10 \%$ tending intensity of 40 -year-old coniferous and broad-leaved mixed plantations in Xishan, Beijing [5]; 3-12 $\mathrm{t} \cdot \mathrm{hm}^{-2} \mathrm{shreds}^{-}$ 
were obtained after $15 \%$ intensity tending of a Platycladus orientalis (L.) Franco plantation aged 15-30 years in Huairou and Fangshan District of Beijing. Feng and others found that tending can cause nutrient loss of $90-190 \mathrm{~kg} \cdot \mathrm{hm}^{-2}$ in the half-mature forest of Platycladus orientalis (L.) Franco, containing about $40 \%$ nitrogen, phosphorus, and potassium $[4,6]$. Composting the tending shreds of Platycladus orientalis (L.) Franco can effectively solve the problem of its large number, which is not easy to deal with, and natural stacking destroys the nutrient balance in the forest.

Composting refers to crushing organic raw materials, artificially controlling water, $\mathrm{C} / \mathrm{N}$ ratio, ventilation, and other conditions, and using microbial fermentation to turn waste into stable, harmless, and nutritious organic fertilizer [7], which has been mature and applied in the fields of green waste, vegetable, and crop organic waste [8-10]. Different treatment combinations, such as rhamnolipid, mushroom residue, earthworm dung, and zeolite, have different effects on the quality of garden greening waste composting products [11,12]. Applying tomato straw compost could not only increase tomato yield, but also improve fruit quality [13]. Tea was studied based on coarse-grained compost, and it was found that compost products had a significant impact on crop growth and health [14]. In contrast, there are few studies on in-situ composting of Platycladus orientalis (L.) Franco, tending shreds into forest organic fertilizer.

Platycladus orientalis (L.) Franco is rich in nutrients and low in bulk density, which is suitable for use as raw material for forest fertilizer [15], but it has a high content of organic macromolecules, such as lignin, cellulose, and secondary metabolites, has a dense three-dimensional network aromatic ring structure and high crystallinity [16], and requires a large amount of cellulose, lignin, Trichoderma and other microbiota, and high vitality [17]. Therefore, the traditional composting method has some disadvantages, such as a long maturity cycle, low temperature in the maturity stage, unstable compost quality, and so on. With the help of exogenous additives, such as fermentation priming $[18,19]$, the structure of composting flora can be improved [20], the activities of microorganisms can be strengthened, the accumulation and growth of microorganisms can be promoted in a short time [21-24], and the quality of composting can be improved. It was found that the decomposition rates of cellulose, hemicellulose, and lignin in the compost increased significantly after adding bacterial agents to the mixed compost of agricultural waste and pig manure [25]. At present, there is no relevant report on the application of Exogenous Additives in the composting utilization of Platycladus orientalis (L.) Franco in tending residue forests.

In this study, the composting process of Platycladus orientalis (L.) Franco tending residue was studied with fermentation priming and common compost as additives. The composting technology suitable for the forest environment was discussed, and the changes of dynamic indexes, nutrient content, and maturity of compost under different additives were compared.

\section{Materials and Methods}

\subsection{Study Site}

The study took place in the Beitaishang Forest Farm $\left(116^{\circ} 70^{\prime} \mathrm{E}, 40^{\circ} 39^{\prime} \mathrm{N}\right)$ in Huairou District, Beijing. In 2014, the Huairou District Landscaping Bureau implemented tending measures, such as cutting and irrigation, planting, and thinning on $0.806 \mathrm{~km}^{2}$ of forest land in the forest farm, with tending intensity of $15-18 \%$ and tending residue of about $45 \mathrm{t}$.

The average altitude of the study area is $91 \mathrm{~m}$ a.s.l. (Above sea level), belonging to the warm temperate semi-humid continental monsoon climate, with an annual average temperature of $7-19^{\circ} \mathrm{C}$. It is hot and rainy in summer and cold and dry in winter and has a short spring and autumn. The annual frost-free period is $180-200$ days, $80 \%$ of the annual precipitation is concentrated in June to August in summer, and the annual average precipitation is $600-700 \mathrm{~mm}$. The main soil types are brown and cinnamon, mostly loamy and sandy, with a soil thickness of $30 \mathrm{~cm}$. The experimental site is dominated by a halfmature Platycladus orientalis (L.) Franco plantation, accompanied by a few broad-leaved 
trees, such as Quercus variabilis Blume. The understory vegetation includes Cotinus coggygria Scop and Vitex negundo Linn. Var. heterophylla (Franch.) Rehd.).

\subsection{Experimental Design}

The tending shreds of Platycladus orientalis (L.) Franco collected in the forest were used as composting raw materials, and the tending raw materials were crushed to a particle size of about $6 \mathrm{~cm}$ (the crusher model is BC 600 XL, VERMEER, Iowa, the United States). The moisture content of the raw material was adjusted to $70 \%$, and urea (Shanghai chaoxuan Chemical Technology Co., Ltd., Shanghai, China) and diamine (64\% total nutrient, 18\% N, 20\% P, Shanghai chaoxuan Chemical Technology Co., Ltd., Shanghai, China) were added to adjust the $\mathrm{C} / \mathrm{N}$ to 40 and $\mathrm{C} / \mathrm{P}$ to 100 (Table 1). Fermentation priming (developed and provided by Beijing Goldenway Biotech Co., Ltd., Beijing, China, and its beneficial viable bacteria number is $\geq 20$ million $\cdot \mathrm{g}^{-1}$, contains lignin enzyme, hemicellulase, etc., organic matter is $\geq 75 \%$, the $\mathrm{pH}$ value range is 5.5-7.5) and common compost (made by traditional composting with Vitex trifolia and cow dung as the main raw materials, with organic matter content of $45 \%$, total nutrient content of $6.4 \%$ and $\mathrm{pH}$ of 7.4 ) were selected as exogenous additives with an additional amount of $0.2 \% \times \mathrm{W}$ reactor mass. A total of 4 randomized blocks were set, each repeated 3 times, respectively:

(1) T1: The compost material $\mathrm{C} / \mathrm{N}, \mathrm{C} / \mathrm{P}$ were adjusted, and $0.2 \%$ priming was added;

(2) T2: The compost material $\mathrm{C} / \mathrm{N}, \mathrm{C} / \mathrm{P}$ were adjusted, and $0.2 \%$ common compost was added;

(3) T3: Adjusted the raw materials $\mathrm{C} / \mathrm{N}$ and $\mathrm{C} / \mathrm{P}$ only, without any additives.

(4) T4 (CK, short for control check): The control check group was composted in situ after crushing the raw materials of tending materials without the regulation of $C, N$, and $P$.

Table 1. Characteristic of Platycladus orientalis (L.) Franco tending shreds.

\begin{tabular}{ccccc}
\hline Tending Shreds & Moisture (\%) & $\mathbf{C} / \mathbf{N}$ & $\mathbf{C} / \mathbf{P}$ & $\begin{array}{c}\text { Total Nutrient } \\
\left.\text { (TN * } \mathbf{K}_{\mathbf{2}} \mathbf{O}+\mathbf{P}_{\mathbf{2}} \mathbf{O}_{5}, \mathbf{\%}\right)\end{array}$ \\
\hline $\begin{array}{c}\text { Before } \\
\text { adjustment }\end{array}$ & 35 & $80: 1$ & $200: 1$ & 3.3 \\
After adjustment & 70 & $40: 1$ & $100: 1$ & 3.5 \\
\hline * TN stands for the abbreviation of Total Nitrogen.
\end{tabular}

* TN stands for the abbreviation of Total Nitrogen.

After the preparation of composting raw materials, we started composting in early May, and the site was selected as the original place inside the forest. We used plastic film to seal the compost (Figure 1) to control the evaporation and heat dissipation of water and effectively retain the heat in the reactor. According to the settings of different treatment groups, raw materials and additives were mixed evenly and stacked into cuboids of about 5-7 $\mathrm{m}^{3}$; We placed the TDR detector (the TDR model is EM50 with ECH2O soil monitoring system, METER, Washington, the United States) detection line in each reactor and covered it with plastic agricultural film. The TDR tester was set to record data every $30 \mathrm{~min}$ and run for $24 \mathrm{~h}$. When it was detected that the temperature of the pile had a peak value and continued to decline, it was turned over once and covered with agricultural film again until the end of composting. 

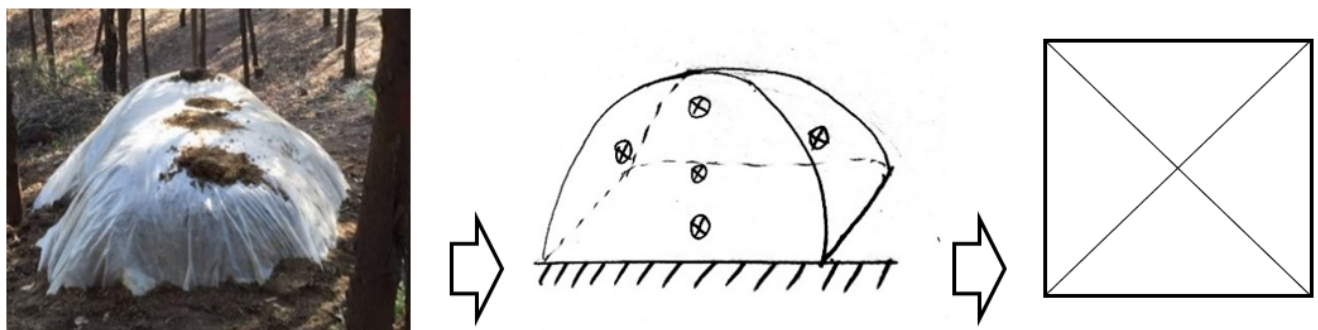

Figure 1. Sample collection. From left to right are photos of composting in Platycladus orientalis (L.) Franco, location of 5 sampling points of mixed samples, and collection of compost mixed samples by quartering method.

\subsection{Sample Collection and Index Determination}

A total of 5 mixed fertilizer samples at the middle, upper, middle, lower, left, and right positions of each pile body were collected after composting (as shown in Figure 1). After the samples were air-dried, they were crushed and screened to $1 \mathrm{~mm}, 0.25 \mathrm{~mm}$, and $0.149 \mathrm{~mm}$.

Temperature, moisture content, electrical conductivity (EC), and degradation rate of wood fiber components were selected as the change indexes of the composting process. The temperature, moisture content, and conductivity were automatically monitored by the TDR detector placed in advance. After composting, the data of moisture content, conductivity, and temperature in the pile in the moisture detector were collected every 2 weeks until the end of composting in the 8th week. The lignocellulosic components in the composting stage were determined by the Van-Soest washing fiber analysis method; after the contents of cellulose, hemicellulose, and lignin were determined, respectively, the degradation rate of each component was calculated [26,27].

$$
\text { Hemicellulose }(\%)=\text { neutral detergent fiber }(\%)-\text { acid detergent fiber }(\%)
$$

Cellulose $(\%)=$ acid detergent fiber $(\%)-$ residue after $72 \%$ sulfuric acid treatment $(\%)$

$$
\text { Lignin }(\%)=\text { residue treated with } 72 \% \text { sulfuric acid }(\%)-\text { ash }(\%)
$$

$\mathrm{PH}$ value, organic matter, total nitrogen $(\mathrm{TN})$, phosphorus $\left(\mathrm{P}_{2} \mathrm{O}_{5}\right)$, potassium $\left(\mathrm{K}_{2} \mathrm{O}\right)$, and total nutrients were selected as indicators of composting quality. Among them, $\mathrm{pH}$ value was determined by a $\mathrm{pH}$ meter (FE28, METTLER TOLEDO, Zurich, Switzerland), and organic matter was determined by Potassium Dichromate Capacity external heating method [28]. After the sample was digested with $\mathrm{H}_{2} \mathrm{SO}_{4}-\mathrm{H}_{2} \mathrm{O}_{2}, \mathrm{TN}$ was measured with a Kjeldahl nitrogen determinator (KDN04A, DECCA, Shenzhen, China) [28], $\mathrm{P}_{2} \mathrm{O}_{5}$ with a spectrophotometer (UV-5600, FUP, Shanghai, China) [28], and $\mathrm{K}_{2} \mathrm{O}$ with a flame photometer (TT5D, FUP, Shanghai, China) [28]. The total nutrient content was obtained by adding TN, $\mathrm{P}_{2} \mathrm{O}_{5}$, and $\mathrm{K}_{2} \mathrm{O}$.

$\mathrm{C} / \mathrm{N}$, germination rate, and germination index $(G I)$ were selected as indicators of the compost maturity stage. One hundred perennial ryegrass seeds (Beijing Academy of agricultural and Forestry Sciences, Beijing, China) were selected for the germination experiment [12,29]. They were cultured at room temperature for $96 \mathrm{~h}$. The number of germinated seeds was counted, and the root length was measured. Each treatment was repeated 3 times. Distilled water was used as the blank control group. Finally, the germination rate and GI of seeds were calculated.

The chemical reagents involved in the experiment are all from Aladdin, which are chemically pure.

Germination rate $(\%)=$ number of germinated seeds $/$ number of tested seeds $\times 100 \%$ 
Germination Index $(\%)=($ seed germination rate of compost extract $) \times$ Seed root length $) /($ seed germination rate of distilled water $\times$ Seed root length) $\times 100 \%$

\subsection{Data Collection}

The data of composting process change indicators (temperature, moisture content, and EC) in the TDR moisture detector were exported. The decomposition rates of cellulose, hemicellulose, and lignin are calculated from Formulas (1)-(3) in Section 2.3; and the Germination Rate and Germination Index were calculated by Formulas (4) and (5) in Section 2.3.

Means and standard deviations of each compost were calculated in Excel 2016 (Office 2016, Microsoft, Redmond, the United States). Four one-way ANOVAs (in SPSS 20.0, Shanghai, China) were used to determine:

(1) The differences in moisture content, EC, and temperature in different treatment groups at each period of composting;

(2) The calculation and drawing of decomposition rates of lignin, cellulose, and hemicellulose in composting;

(3) Indexes, such as nutrient content and maturity of compost, and indexes, such as $\mathrm{pH}$, organic matter, and total nutrient content of compost;

(4) Multiple comparisons were made at the level of 0.05 by Tukey's test to obtain the significant differences of monitoring indicators and fertilizer nutrient content of different treatments in the composting process.

\section{Results}

3.1. Effect of Additives on the Composting Process of Platycladus orientalis (L.) Franco Tending Shreds

\subsubsection{Temperature Variation}

The composting process lasted for 8 weeks, and the average temperature of $\mathrm{T} 1$ and T2 was always higher than that of the other two treatments (Figure 2). The temperature of each treatment first increased with the increase of stacking time, reached its peak around the 6th week, and then decreased gradually. The average temperature variation range of $\mathrm{T} 1$ and T3 was relatively large, with a temperature difference of $4-6^{\circ} \mathrm{C}$; $\mathrm{T} 1$ had the highest peak temperature, more than $50^{\circ} \mathrm{C}$, followed by $\mathrm{T} 2$. The average temperature of $\mathrm{T} 4$ varied from $35.6^{\circ} \mathrm{C}$ to $38.4{ }^{\circ} \mathrm{C}$, with the smallest variation range and the lowest peak value. The difference between the peak temperature of $\mathrm{T} 1$ and that of $\mathrm{T} 4$ was $12.6^{\circ} \mathrm{C}$. In terms of significance, from the beginning of composting to the second week, there was a significant difference between the average temperature of $\mathrm{T} 1$ and $\mathrm{T} 2$ and the other two treatments $(p<0.05)$. At this time, $\mathrm{T} 1$ and $\mathrm{T} 2$ reached more than $45{ }^{\circ} \mathrm{C}$. There was a significant difference between the four treatments from the peak temperature in the 6th week to the end of composting in the 8th week. In conclusion, when priming was used as an additive, the temperature changed most obviously in the composting process, and the peak average temperature was the highest, which could reach the high-temperature decomposition stage; the treatment with common compost had the second highest peak temperature. 


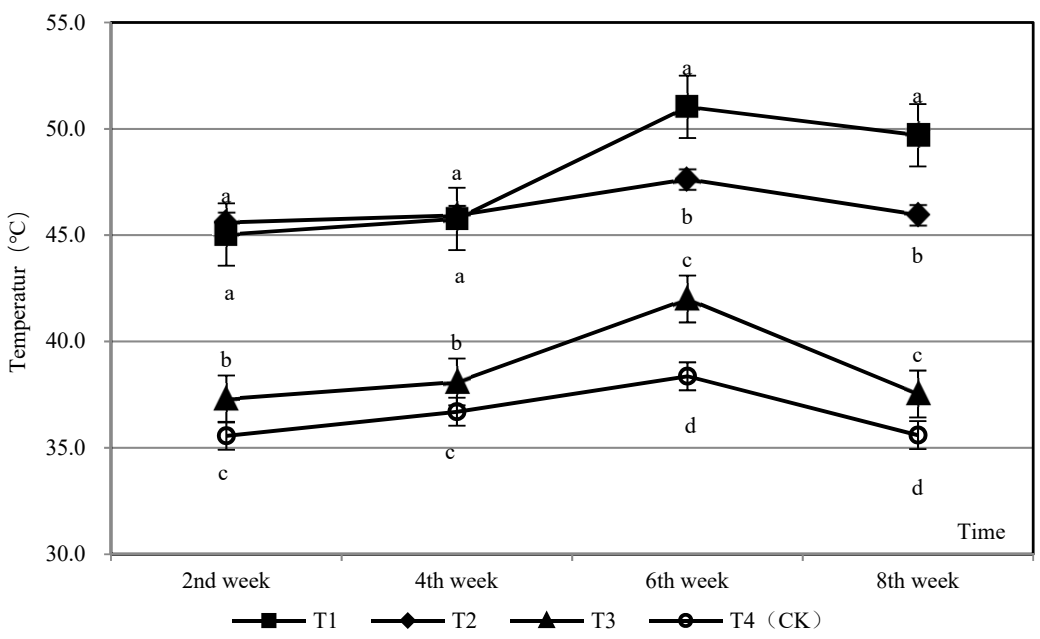

Figure 2. Change of temperature in different treatments. T1: adjust $\mathrm{C} / \mathrm{N}, \mathrm{C} / \mathrm{P}+0.2 \%$ priming; $\mathrm{T} 2$ : adjust $\mathrm{C} / \mathrm{N}, \mathrm{C} / \mathrm{P}+0.2 \%$ common compost; $\mathrm{T} 3$ : adjust $\mathrm{C} / \mathrm{N}, \mathrm{C} / \mathrm{P}$; $\mathrm{T} 4(\mathrm{CK})$ : raw material grinding of tending material. Different letters indicate a significant difference at the 0.05 level.

\subsubsection{Moisture Content}

In the whole composting cycle, the average moisture content of T2 varied by $14 \%$, and the peak reached $57 \%$, with the largest variation and the highest peak. In contrast, T4 had the smallest change, only $4 \%$, which was 1.2 times different from the peak moisture content of T2 (Figure 3). The average moisture content of T2 always maintained an upward trend. T1, T3, and T4 increased first and then stabilized, and the peak appeared in the sixth week. In terms of significance, from the beginning of composting to the second week, the average moisture content of T1, T2, and T3 gradually showed differences from T4 $(p<0.05)$. By the 8th week, there were significant differences among the four treatments. The average moisture content of T2 and T1 was more than 50\%, and the order from high to low was $\mathrm{T} 2>\mathrm{T} 1>\mathrm{T} 3>\mathrm{T} 4$. There was no significant difference between T1 and T3. On the whole, the addition of common compost had the greatest impact on the change of water content in the composting process and at the end of composting, followed by the addition of a detonating agent.

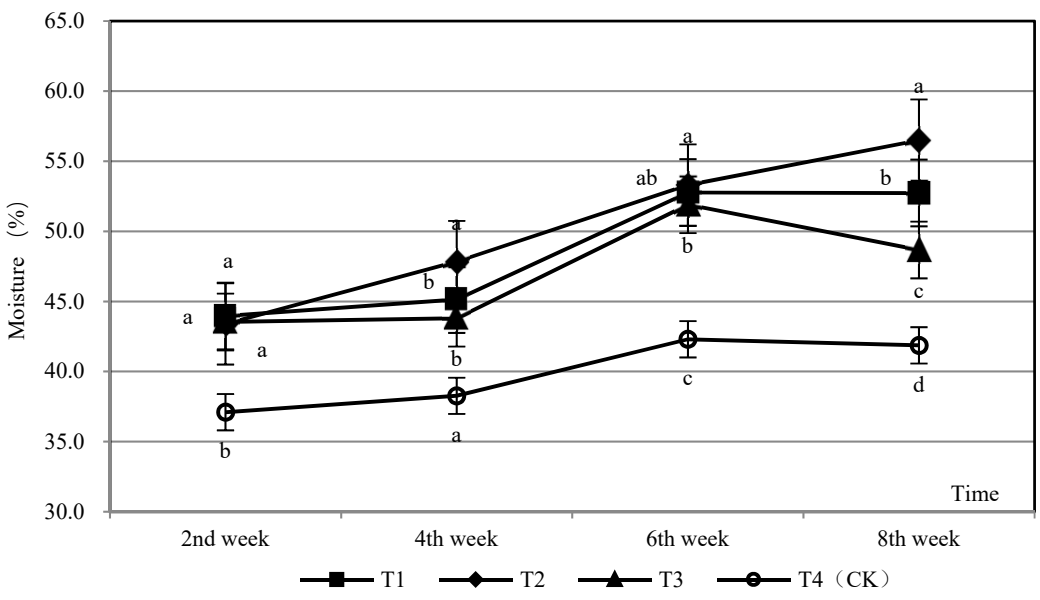

Figure 3. Change of moisture in different treatments. T1: adjust $\mathrm{C} / \mathrm{N}, \mathrm{C} / \mathrm{P}+0.2 \%$ priming; $\mathrm{T} 2$ : adjust $\mathrm{C} / \mathrm{N}, \mathrm{C} / \mathrm{P}+0.2 \%$ common compost; $\mathrm{T} 3$ : adjust $\mathrm{C} / \mathrm{N}, \mathrm{C} / \mathrm{P} ; \mathrm{T} 4(\mathrm{CK})$ : raw material grinding of tending material. Different letters indicate a significant difference at the 0.05 level. 


\subsubsection{Electrical Conductivity (EC) Value}

From the beginning of composting to the end of the 8th week, the average EC values of T1 and T2 were always greater than $1.00 \mathrm{MS} \cdot \mathrm{cm}^{-1}$. In contrast, T1 changed the most and T3 changed the least (Figure 4). T2, T3, and T4 peaked around the 6th week, and the difference between T1 with the highest peak and T4 with the lowest peak was 3.9 times. In addition to the continuous growth of the $\mathrm{T} 1$ average $\mathrm{EC}$ value, the other three treatments increased first and then decreased with time. In terms of significance, the significance of the difference between the treatments changed from large to small and then to large with the composting time. From the second week of composting, the average EC values of T1 and $\mathrm{T} 2$ were significantly different from those of other treatments $(p<0.05)$, and the difference decreased in the middle stage of composting. By week 8 , there was a significant difference in the average EC value between the four treatments. In the whole composting process, the difference between T3 and T4 was not significant. It could be seen that the use of a detonator had the greatest impact on the EC value in the composting process, and the EC value content was the highest at the end of composting; adding common compost followed.

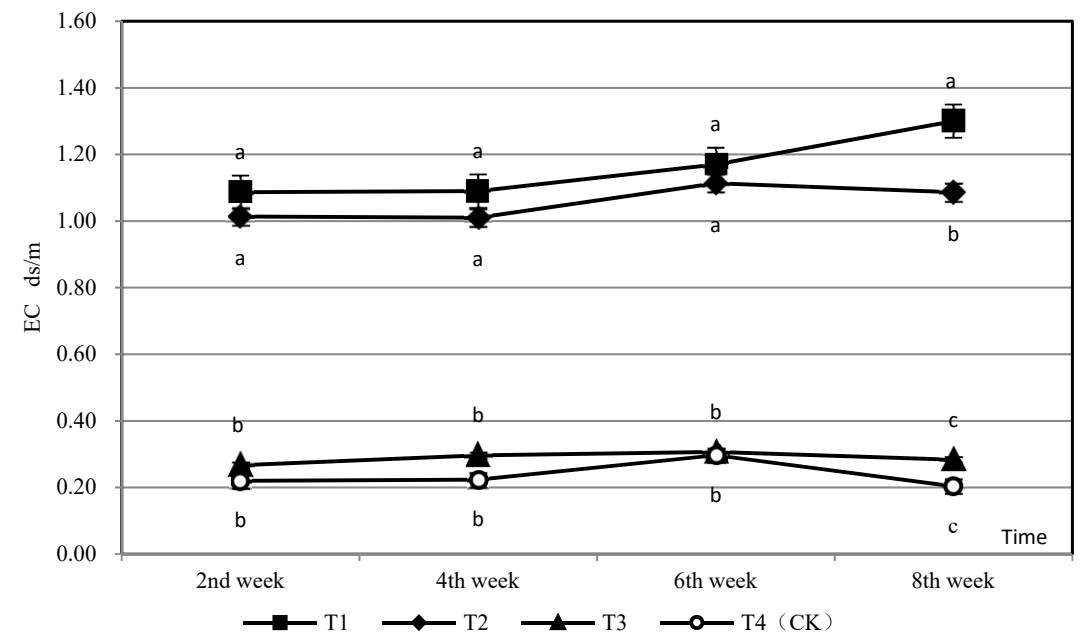

Figure 4. Change of $\mathrm{EC}$ in different treatments. $\mathrm{T} 1$ : adjust $\mathrm{C} / \mathrm{N}, \mathrm{C} / \mathrm{P}+0.2 \%$ priming; $\mathrm{T} 2$ : adjust $\mathrm{C} / \mathrm{N}, \mathrm{C} / \mathrm{P}+0.2 \%$ common compost; $\mathrm{T} 3$ : adjust $\mathrm{C} / \mathrm{N}, \mathrm{C} / \mathrm{P} ; \mathrm{T} 4(\mathrm{CK})$ : raw material grinding of tending material. Different letters indicate a significant difference at the 0.05 level.

\subsubsection{Degradation Rate of Cellulose, Lignin, and Hemicellulose}

From the beginning of composting to the end of the 8th week, the decomposition rate of lignocellulose in each group increased with the accumulation of composting time (Figure 5). The change of cellulose decomposition rate in each stage of composting was similar and showed a continuous growth state, from high to low, T1 > T2 > T3 > T4; at the end of composting, the decomposition rate (Figure 5a) of T1 cellulose was 1.7 times that of T4. The lignin decomposition rate (Figure $5 b$ ) of T2 was the highest in the early stage of composting, which was slightly lower than T1 after 6 weeks. Compared with T4, the lignin decomposition rate of $\mathrm{T} 1$ increased by $5.6 \% \sim 12.5 \%$ in the whole cycle and reached $25.5 \%$ at the end of composting. The decomposition rates of T1 and T2 hemicellulose were always significantly higher than T3 and T4 and began to slow down at the 6th week. In the whole cycle, the hemicellulose decomposition rate (Figure $5 \mathrm{c}$ ) of T2 increased by $18.6 \%$, which was 1.9 times that of T3 and 3.2 times that of T4. It could be seen that the detonator had the most obvious effect on the decomposition rate of cellulose and lignin, and the addition of common compost had a significant effect on the decomposition rate of hemicellulose. 


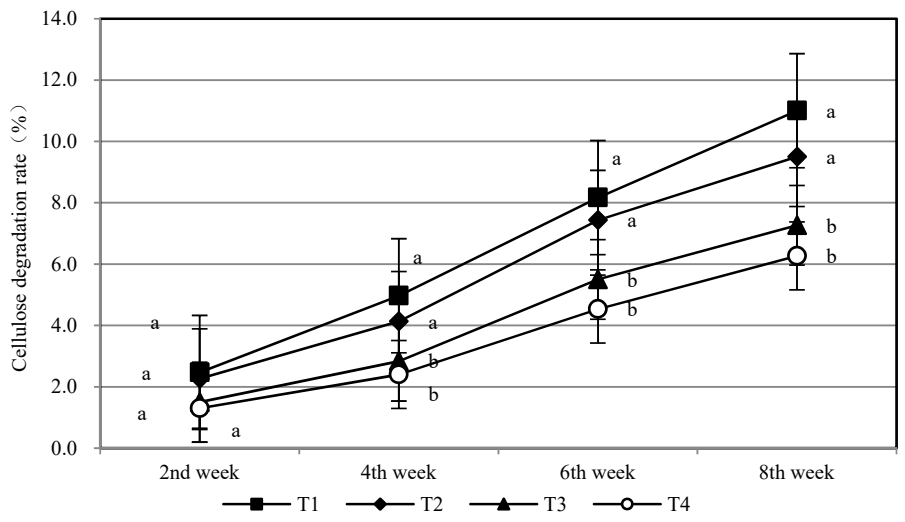

(a)

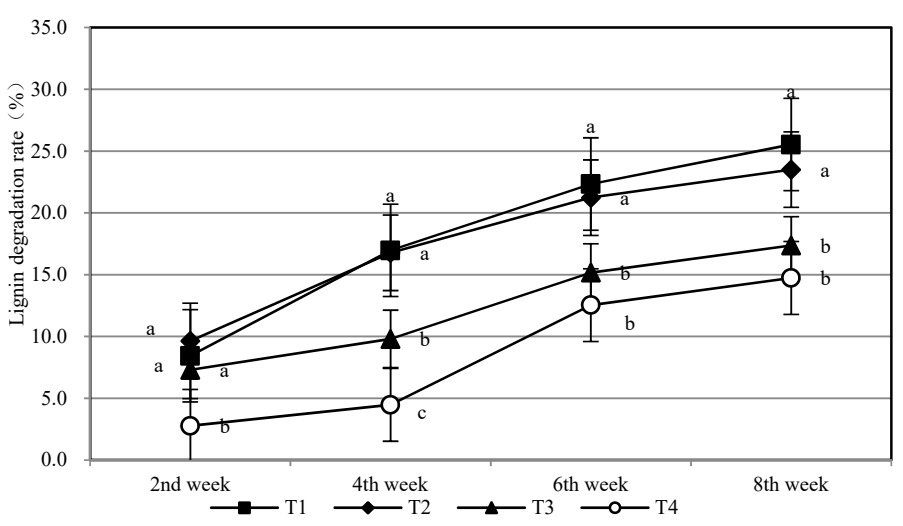

(b)

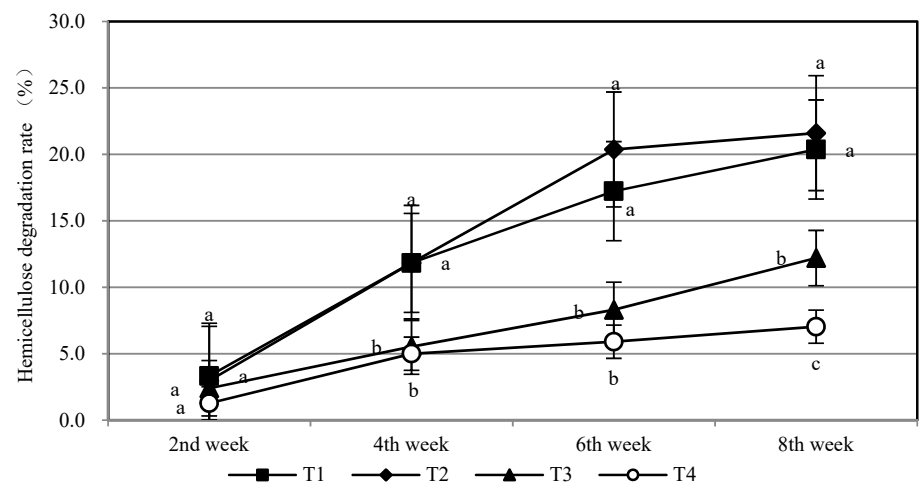

(c)

Figure 5. Change of degradation rate of cellulose (a), lignin (b), and hemicellulose (c) in compost with different treatments. $\mathrm{T} 1$ : adjust $\mathrm{C} / \mathrm{N}, \mathrm{C} / \mathrm{P}+0.2 \%$ priming; $\mathrm{T} 2$ : adjust $\mathrm{C} / \mathrm{N}, \mathrm{C} / \mathrm{P}+0.2 \%$ common compost; T3: adjust $\mathrm{C} / \mathrm{N}, \mathrm{C} / \mathrm{P}$; T4 (CK): raw material grinding of tending material. Different letters indicate a significant difference at the 0.05 level.

3.2. Effect of Additives on Composting Quality of Platycladus orientalis (L.) Franco Tending Shreds

\subsection{1. $\mathrm{pH}$ Value and Organic Matter Content}

At the end of the 8th week, the $\mathrm{pH}$ of $\mathrm{T} 1$ and $\mathrm{T} 2$ reached more than 7.0 , and $\mathrm{T} 1$ was the highest, up to 7.5; in contrast, T4 was the lowest, only 5.9 (Figure 6a). There was no sig- 
nificant difference in $\mathrm{pH}$ between $\mathrm{T} 1$ and $\mathrm{T} 2$, but there was a significant difference between $\mathrm{T} 3$ and T4 $(p<0.05)$. The order of compost $\mathrm{pH}$ from high to low was T1 > T2 > T3 > T4. The average organic matter content of compost in each treatment was significantly different (Figure 6b). Among them, the average organic matter content of T1 was the highest, up to $52 \%$; the organic matter content of $\mathrm{T} 1$ and $\mathrm{T} 2$ had a significant difference, and $\mathrm{T} 2$ and T3 were up to more than 40\%; T4 had the lowest organic matter content, only 30\%, which was 1.7 times higher than T1. On the whole, the addition of a detonating agent and common fertilizer had the most obvious effect on the regulation of compost $\mathrm{pH}$ and had a great impact on promoting the release of organic matter from the raw material of Oriental Arborvitae tending.

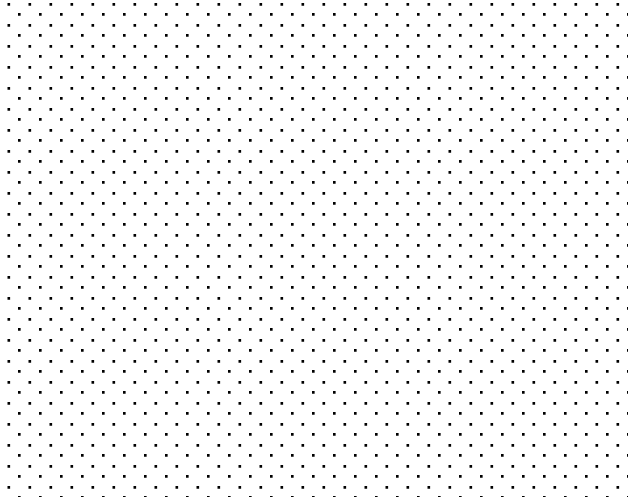

(a)

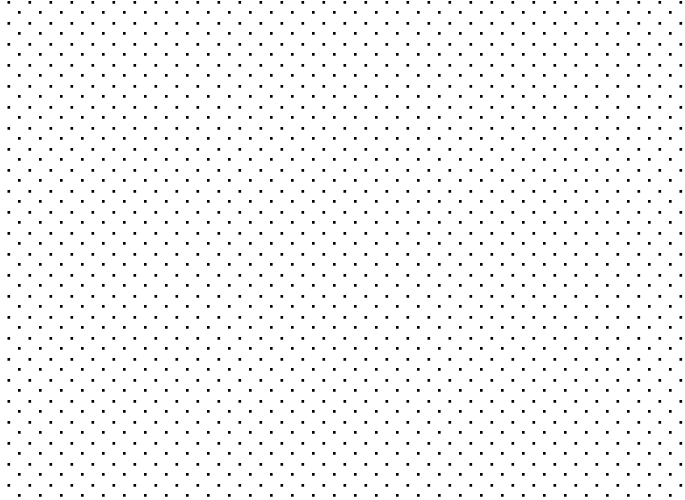

(b)

Figure 6. $\mathrm{pH}(\mathbf{a})$ and the mass fraction of organic matter $(\mathbf{b})$ of different treatments. $\mathrm{T} 1$ : adjust $\mathrm{C} / \mathrm{N}$, $\mathrm{C} / \mathrm{P}+0.2 \%$ priming; $\mathrm{T} 2$ : adjust $\mathrm{C} / \mathrm{N}, \mathrm{C} / \mathrm{P}+0.2 \%$ common compost; $\mathrm{T} 3$ : adjust $\mathrm{C} / \mathrm{N}, \mathrm{C} / \mathrm{P}$; $\mathrm{T} 4 \mathrm{CK}$ ): raw material grinding of tending material. Different letters indicate a significant difference at the 0.05 level.

\subsection{2. $\mathrm{TN}, \mathrm{K}_{2} \mathrm{O}, \mathrm{P}_{2} \mathrm{O}_{5}$, and Total Nutrients}

The nutrient content of raw materials was the same, and there was a great difference in the nutrient content of each compost after 8 weeks (Figure 7). There was no significant difference in total nitrogen (TN) between T1, T2, and T3 and T4; the total nitrogen contents of T2 and T3 were close, and the highest T1 increased by $2.04 \%$ compared with the lowest T4. There was no significant difference in total potassium $\left(\mathrm{K}_{2} \mathrm{O}\right)$ content between $\mathrm{T} 1$ and $\mathrm{T} 2$, but there was a significant difference with the other two treatments; T1 with the highest content is close to twice that of T4 with the lowest content. The content of total phosphorus $\left(\mathrm{P}_{2} \mathrm{O}_{5}\right)$ in each group was close, and the value was between $0.50 \%-0.60 \%$; T3 was the highest on average, up to $0.71 \%$. There was no significant difference among T1, T2, and T4. In terms of total nutrients $\left(\mathrm{TN}+\mathrm{K}_{2} \mathrm{O}+\mathrm{P}_{2} \mathrm{O}_{5}\right)$, the contents of $\mathrm{T} 1$ and $\mathrm{T} 2$ were close, which met the requirements of organic fertilizer for total nutrients $\geq 5.0 \%$, of which $\mathrm{T} 1$ was the highest, up to $5.8 \%$. The difference between the lowest T4 and T1 was 1.8 times. There were significant differences among the average values of total nutrients in each treatment. In conclusion, the decomposition rate of raw materials and nutrient mineralization rate of Platycladus orientalis (L.) Franco tending added with a detonating agent and common compost was the highest, especially in terms of nitrogen, potassium, and total nutrient content. 


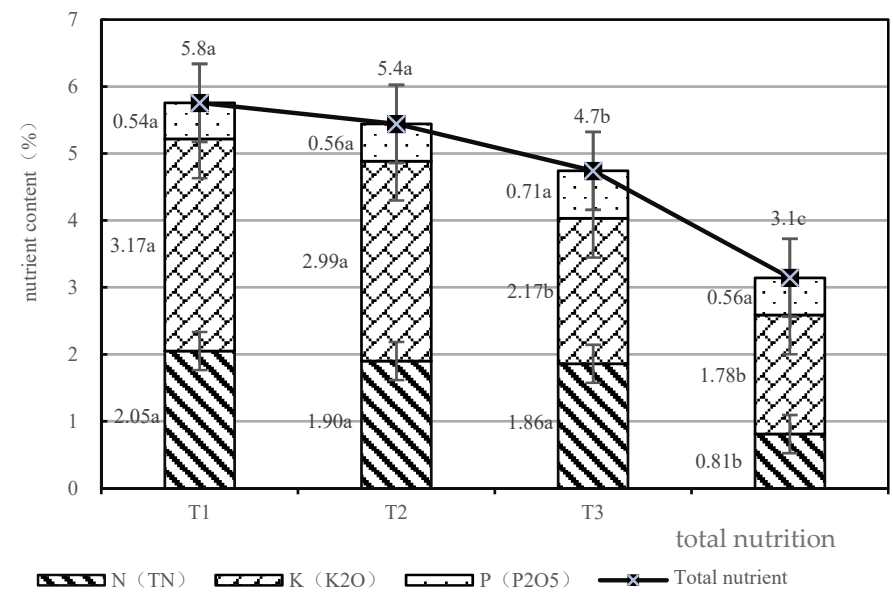

Figure 7. Nutrient content of different treatments. $\mathrm{T} 1$ : adjust $\mathrm{C} / \mathrm{N}, \mathrm{C} / \mathrm{P}+0.2 \%$ priming; $\mathrm{T} 2$ : adjust $\mathrm{C} / \mathrm{N}, \mathrm{C} / \mathrm{P}+0.2 \%$ common compost; T3: adjust $\mathrm{C} / \mathrm{N}, \mathrm{C} / \mathrm{P} ; \mathrm{T} 4(\mathrm{CK})$ : raw material grinding of tending material. Different letters indicate a significant difference at the 0.05 level.

\subsubsection{Compost Maturity Test}

By the end of the 8 th week of fermentation, the $\mathrm{C} / \mathrm{N}$ of $\mathrm{T} 1, \mathrm{~T} 2$, and $\mathrm{T} 3 \mathrm{had}$ not decreased from 40 to below 30 except T4 (Table 2). Relatively speaking, the $\mathrm{C} / \mathrm{N}$ of $\mathrm{T} 3$ is the most ideal, followed by T1. In the application of landscaping waste composting, if GI $>50 \%$, it could be considered that the compost had no toxicity and met the requirements of maturity. This index also had a considerable reference value for forest tending compost. By the 8th week, the GI of each treatment reached more than $60 \%$, reaching the harmless standard; T2 reached $81 \%$, and the degree of maturity was the best. It could be seen that the compost of each treatment had reached the maturity level, but the use of additives effectively reduced the $\mathrm{C} / \mathrm{N}$ of compost and promoted seed germination and root growth; among them, adding common compost had the best maturity, followed by adding the detonating agent.

Table 2. Compost maturity tests of different treatments.

\begin{tabular}{cccc}
\hline Treatments & C/N & $\begin{array}{c}\text { Germination Percentage } \\
\mathbf{( \% )}\end{array}$ & $\begin{array}{c}\text { Germination Index } \\
\mathbf{( \% )}\end{array}$ \\
\hline $\mathrm{T} 1^{*}$ & $23 \pm 0.16 \mathrm{~b}$ & $91 \pm 3.06 \mathrm{a}$ & $69 \pm 1.93 \mathrm{c}$ \\
$\mathrm{T}^{*}$ & $25 \pm 0.21 \mathrm{~b}$ & $92 \pm 4.16 \mathrm{a}$ & $81 \pm 2.33 \mathrm{a}$ \\
$\mathrm{T} 3{ }^{*}$ & $22 \pm 0.68 \mathrm{~b}$ & $88 \pm 0.58 \mathrm{a}$ & $65 \pm 6.82 \mathrm{c}$ \\
$\mathrm{T} 4{ }^{*}$ & $37 \pm 1.82 \mathrm{a}$ & $88 \pm 4.73 \mathrm{a}$ & $77 \pm 7.93 \mathrm{~b}$ \\
\hline
\end{tabular}

* T1: adjust $\mathrm{C} / \mathrm{N}, \mathrm{C} / \mathrm{P}+0.2 \%$ priming; $\mathrm{T} 2$ : adjust $\mathrm{C} / \mathrm{N}, \mathrm{C} / \mathrm{P}+0.2 \%$ common compost; T3: adjust $\mathrm{C} / \mathrm{N}, \mathrm{C} / \mathrm{P}$; $\mathrm{T} 4$ (CK): raw material grinding of tending material. Data are means \pm standard error; different letters in the same item indicate significant difference at the 0.05 level.

\section{Discussion}

\subsection{Effect of Additives on the Composting Process of Platycladus orientalis (L.) Franco Tending Shreds}

Composting temperature is an important index of microbial activity. In this study, the use of additives (T1 and T2) significantly improved the microbial activity and released a large amount of heat in the composting process, while only adjusting raw material $\mathrm{C} / \mathrm{N}$ and $\mathrm{C} / \mathrm{P}$ (T3 and T4) had no obvious effect on the rise of composting temperature, which was consistent with the research results of Ajuna B [24]. Compared with the peak temperature of more than $60^{\circ} \mathrm{C}$ in the composting process of other scholars [16,30-32], the peak temperature of composting in this study is slightly lower, and only the peak temperature of the detonator group can reach the high-temperature decomposition temperature of more than $50{ }^{\circ} \mathrm{C}$. According to the research, when the heap temperature reaches above $45^{\circ} \mathrm{C}$, 
all 400 corn borers in the corn stubble can die within $1 \mathrm{~h}$ [33]. Therefore, in the practical application of composting of tending shreds of Platycladus orientalis (L.) Franco, the peak temperature of $45^{\circ} \mathrm{C}$ and above is acceptable and operable at the present stage, and the compost at this temperature can be judged to have reached the stage of high-temperature maturity. Our study shows that detonating agents and common compost as additives can promote the reactor to reach sufficient temperature levels, provide a suitable environment for microbial quantity accumulation and vitality improvement, and ensure that the compost meets the non-toxic standard. Due to the particularity of Platycladus orientalis (L.) Franco, on the premise of reaching the harmless standard, the lower composting temperature is conducive to the long-term formation of humus and prolongs the timeliness of composting. Studies have shown that the combination of adjusting the $\mathrm{C} / \mathrm{N}$ ratio and additives can prolong the fermentation time in the high-temperature stage of composting [34,35]. As an additive, the detonator has the most obvious effect of rapid temperature rise in a short time, promoting the transition from composting to humification, reaching the high-temperature decomposition stage, and has the strongest ability of insecticidal activity and sterilization.

This study shows that in the process of composting, the average moisture content of most treatments is the highest at the 6th week. It shows that when composting is carried out to the 6th week, the number of microorganisms in the reactor reaches the maximum and the activity is the most intense [32]. The water content of the treatment with common compost reaches the maximum at the end of composting, which may be because the particle size of common compost is large, which increases the space of compost to a certain extent, to enhance the water holding capacity of compost. The water in compost is the basis of microbial metabolism. It can not only dissolve organic matter but also volatilize and dissipate heat and adjust the reactor temperature [7]. The particle size of the raw materials of Platycladus orientalis (L.) Franco tending shreds is relatively large and the macromolecular content is large, which is not easy to decompose compared with the landscaping wastes. Based on the use of additives, this study uses the technical means of covering plastic film to control the volatilization and heat dissipation of water, accelerate the dissolution of organic matter in a short time, and increase the voids, which effectively improves the voids and water holding capacity of Platycladus orientalis (L.) Franco tending compost, to enhance the water retention. The research of some foreign scholars has confirmed the feasibility of this $[36,37]$.

EC represents the content of soluble salt in compost, and a higher EC value in a certain range represents the more stable the compost product is [38,39]. The detonator can effectively promote the release of soluble salt, reduce the loss of nitrogen, retain more nutrients, and the compost quality is the most stable. The EC values of the other three treatments increased first and then decreased, which is consistent with the research results of Tian [40]. This may be because, in the early stage of composting, the raw materials of Platycladus orientalis (L.) Franco are decomposed into small molecules and ions, increasing the EC value, while in the later stage, the soluble salt and EC value are reduced through the volatilization of carbon dioxide, ammonia, and other gases and the formation of humus [41]. Compared with the research results of landscaping waste [11,38], the variation range of EC average value of compost in each treatment in this study is low, which is related to the high content of lignocellulose in the tending residue of Platycladus orientalis (L.) Franco, which inhibits the release of soluble salt to a certain extent. However, by comparing the EC values of composting with two different additives, it can be seen that the use of additives has a significant effect on promoting the release of soluble salt from raw materials, accelerating the decomposition of the tending shreds of Platycladus orientalis (L.) Franco and making up for the limitations of the characteristics of forestry tree species to a certain extent. There was no significant difference between the control group and the treatment only with the regulation of raw materials $C, N$, and $P$, indicating that the regulation of $C / N$ and $C / P$ had no absolute effect on the EC value of compost.

Studies have shown that $[16,42,43]$ the addition of exogenous active microorganisms can accelerate the degradation of lignocellulose and degrade difficult macromolecules 
into small molecular organic matter. Platycladus orientalis (L.) Franco has a high content of organic macromolecules, such as lignin, cellulose, and secondary metabolites, a large amount of cellulose, lignin, Trichoderma, and other microbiota required for decomposition, and high activity requirements [8], while the specific surface area of branches and leaves is small, which can provide a limited attachment surface for microorganisms, thus affecting the quantity accumulation and activity of microorganisms. The degradation rate of lignocellulose in compost increased by 5.6-18.6\% after using a detonating agent and common compost as additives. It can be seen that additives can accelerate the decomposition of Platycladus orientalis (L.) Franco raw materials, provide greater microbial attachment space, and significantly improve the degradation rate of lignin and cellulose, which is consistent with the research results of other scholars [24,26,31,44]. In this study, the effect of the detonator on the decomposition rate of cellulose and lignin was obvious, and the common compost had a significant effect on accelerating the decomposition rate of hemicellulose. This may be because hemicellulose is relatively unstable, the detonator can provide a relatively stable microbial environment, make the ability to compost to release lignin more lasting, and the decomposition of hemicellulose is slower.

\subsection{Effect of Additives on Composting Quality of Platycladus orientalis (L.) Franco Tending Shreds}

This study shows that the $\mathrm{pH}$ range of each group of compost increased by the end of composting, reaching the $\mathrm{pH}$ range standard with the highest microbial number and activity. This is because microbial metabolism can help produce actinomycetes and fungi conducive to lignin and cellulose decomposition in the early stage of composting [7,8], and help produce alkaline substances and organic acid degradation in the later stage, to improve the $\mathrm{pH}$ value [27,42]. The use of additives can help Platycladus orientalis (L.) Franco tending compost maintain a good microbial acid-base environment, while the treatment without additives is still in an acidic environment in the later stage of composting, affecting the composting quality, which is consistent with the research results of previous scholars $[12,40]$. The $\mathrm{pH}$ value range of the biological detonator added in this study is $5.5-7.5$, and the $\mathrm{pH}$ range of compost in each treatment group is 5.9-7.5. According to the research results of some researchers, composting is consistent with the microbial activity range, which is more conducive to metabolism and degradation [45], so the detonator is very suitable for promoting the composting treatment of Platycladus orientalis (L.) Franco tending. At present, the standard range of $\mathrm{pH}$ of organic fertilizer is 5.5-8.5, and the standard range of $\mathrm{pH}$ of domestic waste and landscaping waste is 7.0-8.0. There is little research on composting of forest tending shreds, and the $\mathrm{pH}$ index can only be used as a necessary but not sufficient condition for composting maturity, so there is no written $\mathrm{pH}$ standard for composting Platycladus orientalis (L.) Franco tending shreds for reference. The results of this study can provide a practical production basis for the $\mathrm{pH}$ standard of composting application of Oriental Arborvitae tending shreds.

In this study, there is no significant difference in phosphorus between the treatment with additives and the control group, indicating that the use of additives has a certain inhibitory effect on phosphorus accumulation, which is consistent with the research results of Zhang et al. [46]. According to the research results of Babett, microbial agents can bring visible nitrogen content increases [47]. However, in this study, there was a significant difference in total nitrogen between each treatment and the control group, and there was no significant difference between the three treatments, which was similar to some research results $[48,49]$. The reason may be that microbial addition will stimulate the activity of nitrogen-containing compounds [50], and metabolism will produce a certain amount of ammonia, resulting in nitrogen loss [8]; however, at the same time, the use of foreign aid additives effectively enhances nitrification and inhibits denitrification to reduce nitrogen loss. Therefore, based on adjusting $\mathrm{C} / \mathrm{N}$ and $\mathrm{C} / \mathrm{P}$, the use of additives has little effect on the increase of total nitrogen. In terms of total nutrients, the total nutrients treated with the detonating agent and common compost reached the organic fertilizer standard of more than $5.0 \%$. A large number of microbiota in the detonator can effectively accelerate the 
mineralization rate of raw materials and greatly improve the effective nutrients and quality of compost. Compared with composting materials, the total nutrient content of the control group decreased slightly after composting. This is because in the process of composting in the forest, the bottom of the pile is in direct contact with the soil, and some nutrients will be immersed into the soil with water. Without the help of foreign microorganisms, the caresses of Platycladus orientalis (L.) Franco in the control group decompose slowly, and the loss of nutrients is faster than that of supplements.

Immature compost products contain phytotoxic substances, which inhibit plant growth. Therefore, by observing the germination of plant seeds in compost products, we can accurately judge whether they are rotten and contain toxic substances [12,29]. Generally, GI and $\mathrm{C} / \mathrm{N}$ ratios are selected as the main indicators to judge the biological toxicity, nitrification, and mineralization of compost [51]. The results showed that the GI of each treatment was more than $60 \%$, reaching the subsidiary standard. Without additives, the compost of Oriental Arborvitae tending can reach a harmless level, but additives, such as detonating agents and common compost, can significantly promote seed germination and plant root growth, consume carbon sources, and reduce nitrogen loss. Compared with the research results of other scholars with $\mathrm{C} / \mathrm{N}<20$ [51,52], the $\mathrm{C} / \mathrm{N}$ of each treatment at the end of composting in this study is slightly higher, which may be because the initial $\mathrm{C} / \mathrm{N}$ adjustment of raw materials is not very low, and the space is limited. However, in the practical application of Platycladus orientalis (L.) Franco tending compost, a higher initial C/ $\mathrm{N}$ in a reasonable range is more favorable. On the one hand, the content of lignocellulose in the tending residue of Platycladus orientalis (L.) Franco is high, and the low initial C/N is not conducive to the formation of slow-release compost in the later stage, which affects the long-term and lasting formation of humus after composting; on the other hand, the forest environment is complex and difficult to operate. Artificially adjusting the low initial C/N will consume a lot of human and material resources, which greatly reduces the cost performance of Platycladus orientalis (L.) Franco tending compost in the forest.

\section{Conclusions}

This study discussed the technical means suitable for composting and applied exogenous additives in the composting of Platycladus orientalis (L.) Franco tending shreds in a forest. The main advantages are reflected in two aspects: (1) The addition of detonator and common compost greatly increased the number and activity of microorganisms in the compost of Platycladus orientalis (L.) Franco tending shreds, so it effectively destroyed the structure of lignin, cellulose, and other non-decomposable substances of Platycladus orientalis (L.) Franco; (2) The use of exogenous additives provides a certain amount of nutrients for the raw materials of Platycladus orientalis (L.) Franco tending in the process of composting and promotes the metabolism of microorganisms and the rapid decomposition of organic materials. In general, based on adjusting the $\mathrm{C} / \mathrm{N}$ and $\mathrm{C} / \mathrm{P}$ of crushed raw materials, the purpose of high-temperature sterilization can be achieved by artificially adjusting the moisture content and covering with agricultural film to accelerate the temperature rise, shorten the natural decomposition cycle of several years to 2-3 months, and effectively speed up the composting process of Platycladus orientalis (L.) Franco tending products; the overall effect of adding a detonator is better than adding common compost.

Author Contributions: L.N. and X.L. conceived and designed the experiments; X.L., J.Z. (Jiwei Zhang) and J.H. participated in the discussion of design and made contact with the study site; F.M. provided human support in Beitaishang state forest farm. H.B. and J.Z. (Jialei Zhu) performed the experiments; X.L. collected samples and analyzed the data; X.L. wrote the paper. All authors have read and agreed to the published version of the manuscript.

Funding: 2015BAD07B00(2015BAD07B02), Key Technologies R\&D Program of China.

Institutional Review Board Statement: Not applicable.

Informed Consent Statement: Not applicable. 
Data Availability Statement: Not applicable.

Acknowledgments: This work was supported by the Key Technologies R\&D Program of China, 2015BAD07B00(2015BAD07B02). Additional support was provided by the Beitaishang state forest farm and Gardening and Greening Bureau, Beijing.

Conflicts of Interest: The authors declare no conflict of interest.

\section{References}

1. Department of Planning and Finance, State Forestry and Grassland Administration. 2018 National Forestry and Grassland Development Statistical Bulletin. EB/OL. 2019. Available online: www.forestry.gov.cn/main/62/20190620/103505752690882.html (accessed on 21 June 2019).

2. Mao, B. Studies on Tending Technology of Young and Half Matured Planted Scenic Forest of Pinus tabulaeformis and Platycladus orientalis (L.) Franco in Beijing. Ph.D. Thesis, Beijing Forestry University, Beijing, China, 2015.

3. Chen, X.A. Utilization and development of forest tending shreds. J. Green Sci. Technol. 2013, 6, 33-34. [CrossRef]

4. Yao, Y.T. Studies on the Biomass and Nutrient Cycling of the Mixed Plantation of Pinus tabulaeformis and Platycladus orientalis (L.) Franco in Xishan Region, Beijing. J. Beijing For. Univ. 1989, 2, 38-46.

5. Yan, H.P.; Li, T. Preliminary Study on Treatment of Stand Tending Slashes in Landscape Forest of Xishan Forest Farm. For. Resour. Manag. 2005, 4, 62-65.

6. $\quad$ Feng, H.Y.; Du, M.Y.; Xin, X.B.; Gao, X.; Zhang, L.J.; Kong, Q.Y.; Fa, L.; Wu, D. Seasonal variation in C, N, and P stoichiometry of Platycladus orientalis (L.) Franco plantation in the rocky mountainous areas of North China. Acta Ecol. Sin. 2019, 39, 1572-1582. [CrossRef]

7. Han, H.G.; Du, K.; Ding, J.Y.; Cai, L.F. Research Progress on Compost Application and Technologies of Garden Waste. J. Shanxi Agric. Sci. 2018, 46, 2111-2114.

8. Huang, J.Z. Research Progress of Microbe in Agricultural Waste Composting. Guangdong Agric. Sci. 2019, 46, 64-70. [CrossRef]

9. Liu, Y.; Zhao, J.Y.; Zhou, W.L.; Qi, Z.Y. Progress on Resource Utilization of Urban Garden Waste. Environ. Sci. Technol. 2020, 43, 32-38. [CrossRef]

10. Yang, D.Y.; Feng, H.P.; Xie, H.; Sang, T. Effect of Different Manure on Ageing Quality of Tomato shreds Composting. J. Inn. Mong. Agric. Univ. 2020, 41, 19-24. [CrossRef]

11. Zhang, L.; Sun, X.Y. Improving green waste composting by the addition of sugarcane bagasse and exhausted grape marc. Bioresour. Technol. 2016, 218, 335-343. [CrossRef]

12. Zhang, L. The Process Control of Green Waste Composting and the Improvement and Application of Compost Product. Ph.D. Thesis, Beijing Forestry University, Beijing, China, 2015.

13. Hu, X.T.; Chen, D.Y.; Niu, B.Y.; Fu, S.T.; Xin, X.; Yang, Z.C. Effects of tomato straw compost on tomato growth, yield and quality. Jiangsu Agric. Sci. 2019, 47, 108-111. [CrossRef]

14. Ugo, D.C. Agricultural waste recycling in horticultural intensive farming systems by on-farm composting and compost-based tea application improves soil quality and plant health: A review under the perspective of a circular economy. Sci. Total Environ. 2020, 738,139840 . [CrossRef]

15. Jin, X. Effect of Tending Residue Compost on Seedings of Platyladus orientalis and Pinus tabulaeformis. Master's Thesis, Beijing Forestry University, Beijing, China, 2016.

16. Wu, X.S.; Li, Z.X.; Huang, Y.L.; Ma, J.; Han, X.B.; Zhang, F. Screening, Identification and Its Composting Application of High-temperature Strain for Degrading Lignocellulose. Anhui Agric. Sci. 2021, 49, 68-71.

17. Yang, C.; Liu, Y.; Chen, X.; Wang, W.W. Effect of fungal communities on litter decomposition under Pinus tabulaeformis artificial forests. J. Cent. South Univ. For. Technol. 2016, 36, 41-47.

18. Wang, J.Q.; Liu, Z.P.; Xia, J.H.; Chen, Y.P. Effect of microbial inoculation on physicochemical properties and bacterial community structure of citrus peel composting. Bioresour. Technol. 2019, 291, 121843. [CrossRef] [PubMed]

19. Bustamante, M.A.; Restrepo, A.P.; Alburquerque, J.A.; Pérez-Murcia, M.D.; Paredes, C.; Moral, R.; Bernal, M.P. Recycling of anaerobic digestates by composting: Effect of the bulking agent used. Clean. Prod. 2013, 47, 61-69. [CrossRef]

20. Chen, Q.Y.; Yang, L.J.; Wu, S.C.; Hu, Y.Y. Research progress of landscaping waste composting technology. Agric. Technol. 2021, 41, 139-142. [CrossRef]

21. Li, C.N.; Su, M.; Yao, T.; Han, Q.Q.; Liang, J.J.; Ran, F.; Liu, Z.Y.; Liu, Y.Z.; Chai, S.J.; Gun, S.B. Effects of microbial agents on physicochemical properties and dominant bacterial communities during pig manure composting. J. Plant Nutr. Fertil. 2020, 26, $1600-1611$.

22. López-González, J.A.; Suárez-Estrella, F.; Vargas-García, M.C.; López, M.J.; Jurado, M.M.; Moreno, J. Dynamics of bacterial microbiota during lignocellulosic waste composting: Studies upon its structure, functionality, and biodiversity. Bioresour. Technol. 2015, 175, 406-416. [CrossRef]

23. Xi, B.D.; Zhao, X.Y.; He, X.S.; Huang, C.H.; Tan, W.B.; Gao, R.T.; Zhang, H.; Li, D. Successions and diversity of humic-reducing microorganisms and their association with physical-chemical parameters during composting. Bioresour. Technol. 2016, 219, 204-211. [CrossRef] 
24. Arjuna, B.H.; Chaw, E.H.M.; Kil, Y.K. Metagenomic analysis reveals enhanced biodiversity and composting efficiency of lignocellulosic waste by thermoacidophilic effective microorganism (tEM). J. Environ. Manag. 2020, 276, 111252. [CrossRef]

25. Wang, Z.H.; Wang, J.T.; Liu, L.; Lu, Y.; Lu, G.X. Effect of Compound Microbial Agent on Composting Process of Rape Straw and Pig Manure. Qinghai Agric. For. Sci. Technol. 2021, 4, 69-73.

26. Meng, T.Y.; Li, S.Y.; Zou, R.S.; Yu, K.F.; Fu, B.Y.; Jie, Y. Effects of immobilized lignin-degrading bacteria on garden waste composting. J. Zhejiang A F Univ. 2021, 38, 38-46.

27. Sun, P.; Sun, W.X.; Wang, B.; Shi, Z.C.; Gong, H.J. Study on the degradation effect of different microbial treatments on lignocellulose. Green Technol. 2020, 16, 234-237. [CrossRef]

28. Bao, S.D. Soil Agro-Chemistrical Analysis; China Agriculture Press: Beijing, China, 2007.

29. Kang, J.L. Effects of Different Composting Methods on the Maturity Characteristics of Organic Materials. Master's Thesis, Hunan Agricultural University, Changsha, China, 2020.

30. Yu, J.; Dong, L.; Xiao, C.Z.; Song, Y.L.; Hong, P.Z.; Li, Y.H.; Chen, S.G.; Ding, F.J. Effects of Different Decomposition Agent on Compost. Humic. Acid 2018, 5, 19-23, 40.

31. Chung, W.J.; Chang, S.W.; Chaudhary, D.K.; Shin, J.D.; Kim, H.; Karmegam, N.; Govarthanan, M.; Chandrasekaran, M.; Ravindran, B. Effect of biochar amendment on compost quality, gaseous emissions and pathogen reduction during in-vessel composting of chicken manure. Chemosphere 2021, 283, 131129. [CrossRef]

32. Gong, X.Q. Effect of Exogenous Additives on earthworm composting of garden waste. Ph.D. Thesis, Beijing Forestry University, Beijing, China, 2019.

33. Zhang, Y.N. Studies on the Foundation of Simple Indexes and Mensuration of Compost Maturity. Master's Thesis, China Agricultural University, Beijing, China, 2004.

34. Chang, H.Q.; Zhu, X.H.; Wu, J.; Guo, D.Y.; Zhang, L.H.; Fang, Y. Dynamics of microbial diversity during the composting of agricultural straw. J. Integr. Agric. 2021, 20, 1121-1136. [CrossRef]

35. Yun, C.X.; Yan, C.R.; Xue, Y.H.; Xu, Z.Y.; Jin, T.; Liu, Q. Effects of Exogenous Microbial Agents on Soil Nutrient and Microbial Community Composition in Greenhouse-Derived Vegetable Straw Composts. Sustainability 2021, 13, 2925. [CrossRef]

36. Tong, B.X.; Wang, X.; Wang, S.Q.; Ma, L.; Ma, W.Q. Transformation of nitrogen and carbon during composting of manure litter with different methods. Bioresour. Technol. 2019, 293, 122046. [CrossRef]

37. Teixeira, D.L.; de Matos, A.T.; Melo, E.D.C. Resistance to forced airflow through layers of composting organic material. Waste Manage. 2019, 36, 57-62. [CrossRef] [PubMed]

38. Jumnoodoo, V.; Mohee, R. Evaluation of FTIR spectroscopy as a maturity index for herbicide-contaminated composts. Environ. Waste Manag. 2011, 9, 89-99. [CrossRef]

39. Karak, T.; Bhattacharyya, P.; Paul, R.K.; Das, T.; Saha, S.K. Evaluation of composts from agricultural wastes with fish pond sediment as bulking agent to improve compost quality. Clean-Soil Air Water 2013, 41, 711-723. [CrossRef]

40. Tian, Y.; Wang, H.Y.; Sun, X.Y.; Yu, Z.; Cao, J.X.; Zhang, L.; Zhao, K. Effects of bamboo vinegar and bacterial reagent addition on the physicochemical properties of green wastes compost. Trans. CSAE 2010, 26, 272-278. [CrossRef]

41. Wang, Z.J. Effects of Different Additives on Garden Waste Composting. Master's Thesis, Dalian University of Technology, Dalian, China, 2019.

42. Zhang, L.; Cao, Y.B.; Wang, W.S.; Zhang, X.Y.; Wang, X.; Yao, P.Q.; Liu, S.; Wang, H.; Ma, L. Effect of chicken manure addition on humification of vegetable waste in composting process composting process. Chin. J. Eco-Agric. 2022, 30, 258-267. [CrossRef]

43. Zhu, N.; Zhu, Y.Y.; Li, B.Q.; Jin, H.M.; Dong, Y.W. Increased enzyme activities and fungal degraders by Gloeophyllum trabeum inoculation improve lignocellulose degradation efficiency during manure-straw composting. Bioresour. Technol. 2021, 337, 125427. [CrossRef] [PubMed]

44. Fu, B.Y.; Sun, X.Y.; Yu, K.F.; Li, S.Y. Construction of special solid composite bacteria for degradation of garden waste and Its Composting effect. Environ. Sci. Res. 2021, 34, 1231-1237. [CrossRef]

45. Yang, J.; Wei, S.Z. Promoting effect of additional lignocellulose decomposing bacteria on the composting system in plateau environment. Tibet. Sci. Technol. 2021, 10, 29-34.

46. Zhang, X.X.; Liu, Z.W.; Zhu, Z.H.; Du, L.Z. Effects of mixed decomposition of leaf litters from Platycladus orientalis (L.) Franco and other trees on nutrient release. Acta Pedol. Sin. 2013, 50, 178-185.

47. Babett, G.; Jenő, S.; Ágnes, V.; Erika, L.; András, S.; László, V. Effect of bacterial inoculation on co-composting of lavender (Lavandula angustifolia Mill.) waste and cattle manure. 3 Biotech 2021, 11, 306. [CrossRef]

48. Wang, S.P.; Wang, L.; Sun, Z.Y.; Wang, S.T.; Shen, C.H.; Tang, Y.Q.; Kida, K. Biochar addition reduces nitrogen loss and accelerates composting process by affecting the core microbial community during distilled grain waste composting. Bioresour. Technol. 2021, 337, 125492. [CrossRef] [PubMed]

49. Wang, X.J.; Zhang, W.M.; Chang, X.Y.; Yin, S.Q.; Hai, L. Microbiological mechanism of reducing carbon and nitrogen loss by composting additives. Acta Sci. Circumstantiae 2021, 41, 4116-4127. [CrossRef]

50. Hu, T.; Wang, X.J.; Zhen, L.S.; Gu, J.; Song, Z.L.; Sun, W.; Xie, J. Succession of diazotroph community and functional gene response to inoculating swine manure compost with a lignocellulose-degrading consortium. Bioresour. Technol. 2021, $337,125469$. [CrossRef] [PubMed] 
51. Bao, Y.Y.; Zhou, Q.X.; Yan, L.; Guan, L.Z. Changes in hippuric acid in composting processes of different animal bird manure. China Environ. Sci. 2007, 5, 642-647. [CrossRef]

52. López-López, N.; López-Fabal, A. Compost based ecological growing media according EU eco-label requirements. Sci. Hortic. 2016, 212, 1-10. [CrossRef] 